TITLE:

\title{
Alternative redo sternotomy in a patient with tracheostoma and patent grafts.
}

\section{$\operatorname{AUTHOR}(S)$ :}

Uehara, Kyokun; Minakata, Kenji; Funamoto, Masaki; Yamazaki, Kazuhiro; Marui, Akira; Sakata, Ryuzo

\section{CITATION:}

Uehara, Kyokun ... [et al]. Alternative redo sternotomy in a patient with tracheostoma and patent grafts.. Asian cardiovascular \& thoracic annals 2014, 22 (7): 852-854

\section{ISSUE DATE:}

2014-09

URL:

http://hdl.handle.net/2433/191014

\section{RIGHT:}

c The Author(s) 2013. Reprints and permissions:sagepub.co.uk/journalsPermissions.nav DOI:10.1177/0218492313486902; This is not the published version. Please cite only the published version.; この論文は出版社版でありません。引用の際には出版社版をご確認 ご利用ください。 
Alternative redo sternotomy technique in a patient with a tracheostoma and patent grafts

Kyokun Uehara, MD

Kenji Minakata, MD, PhD

Masaki Funamoto, MD

Kazuhiro Yamazaki, MD, PhD

Ryuzo Sakata, MD, PhD

From: Department of Cardiovascular Surgery, Kyoto University Graduate School of Medicine,

54 Shogoin Kawahara, Sakyo-ku, Kyoto 606-8507, Japan

Keywords: reoperation, CABG, tracheostoma, surgery/exposure

\section{Address for reprints:}

Kenji Minakata, MD, Department of Cardiovascular Surgery, Kyoto University Graduate School

of Medicine, 54 Shogoin Kawahara-cho, Sakyo-ku, Kyoto 606-8507, Japan

TEL; +81-75-751-3784,

FAX; +81-75-751-3098,

E-mail: minakata@kuhp.kyoto-u.ac.jp

Word count: 1254 


\begin{abstract}
: (95 words)
We describe a redo operation in a patient with a tracheostoma and patent bypass grafts to the coronary arteries. Preoperative investigations revealed that the patent's right internal thoracic artery graft ran directly under the sternum just anterior to the ascending aorta, and the saphenous vein graft was adhering to the surgical wire. In order to prevent injury to the patent grafts and cardiac structures, and to avoid communication with the tracheostoma, the redo procedure was performed via an anterior minithoracotomy combined with a low T-shaped partial sternotomy. The reoperation was successfully completed without any complications.
\end{abstract}




\section{Text}

A median sternotomy in redo cardiac surgery for patients with a tracheostoma can be challenging and carries an increased risk of lethal hemorrhage, airway injury, and deep sternal wound infection. Herein, we report on an alternative redo sternotomy technique in a patient with a permanent tracheostoma who had previously undergone mitral valve replacement (MVR) and coronary artery bypass grafting (CABG).

\section{Clinical summary}

A 71-year-old man with a permanent tracheostoma was referred to our institution following worsening of heart failure due to prosthetic valve endocarditis. The patient had undergone CABG combined with MVR at another institution 13 months prior to the presentation at our hospital. During the CABG, the left internal thoracic artery (LITA) was grafted to the diagonal branch of the left anterior descending artery (LAD), and the right internal thoracic artery (RITA) was grafted to the LAD. In addition, two great saphenous vein grafts were placed to bypass the obtuse marginal branch and the right posterior descending artery. Of note, the RITA was routed anterior to the ascending aorta and was not covered with pericardium on chest closure. Postoperatively, the patient suffered multiple complications including acute kidney failure, ventricular arrhythmia, and respiratory failure requiring prolonged mechanical ventilation. Subsequently, he underwent the 
creation of a permanent tracheostoma. An implantable cardioverter-defibrillator (ICD) was also implanted 6 months after the first cardiac surgery. Echocardiographic investigations performed after the first surgery revealed a mobile mass on the prosthetic mitral valve and the ICD was removed 4 months after the implantation because of a pocket infection caused by Methicillin-resistant Staphylococcus aureus (MRSA). The patient's condition deteriorated despite effective medical treatment for MRSA. Therefore, we decided to perform redo MVR.

A preoperative coronary CT angiogram showed that all bypass grafts were patent (Figure 1). However, it also revealed that the RITA graft ran directly under the sternum just anterior to the ascending aorta, and that the proximal part of the saphenous vein graft was adhering to the surgical wire that had been fixed during the previous surgery. In order to prevent injury to the grafts and the cardiac structures and to avoid communication with the tracheostoma, a redo procedure was planned via an anterior minithoracotomy combined with a low T-shaped partial sternotomy.

Upon the induction of general anesthesia, the patient was switched from tracheal to oral intubation. He was then prepped and draped in the usual fashion. Next, a 6-cm right anterior thoracotomy was performed in the third intercostal space. The pleura were opened, a retractor 
was placed, and the adhesive tissues on the posterior wall of the manubrium and sternum were separated carefully from the right pleural cavity. After visually confirming the existence of sufficient space under the posterior wall of the sternum, a lower midline skin incision was made 5 cm caudal to the tracheostomy. A T-shaped lower sternotomy was completed using an oscillating saw. During the sternotomy, peripherally inserted cardiopulmonary bypass (CPB) via the femoral artery and vein was established for a short period of time, and after the completion of the sternotomy, CPB was weaned off. Following the dissection of the adhesive tissues surrounding the heart, the superior and inferior vena cava were taped and CPB was resumed with additional superior venous cannulation. The RITA and LITA were identified and clamped, and then antegrade cardioplegic solution was delivered after aortic cross-clamping. Then, via a right-sided left atriotomy, the infected prosthetic mitral valve and mobile vegetation were removed and a porcine tissue valve was inserted and sutured in place. Although the RITA graft seemed to be patent, several narrow points were observed, therefore, an additional CABG to the LAD was performed using a piece of saphenous vein. The aortic cross-clamp time and CPB time were 114 minutes and 222 minutes, respectively. The operation was completed without any injury to the patent grafts or cardiac structures. The postoperative course was uneventful, and the patient has been doing well with no surgical site infection or recurrent endocarditis for 6 months postoperatively. 


\section{Discussion}

Occasionally, patients with a permanent tracheostoma require cardiac surgery but possible communication between the tracheostoma and cardiac structures increases the risk of sternal wound infection and mediastinitis. ${ }^{1.2}$ In addition, a complete median sternotomy performed during reoperative procedures increases the risk of hemorrhage because of severe adhesion of bypass grafts in addition to cardiac chambers and great vessels to the posterior sternal wall, especially in patients with previous history of CABG..$^{3-5}$

Several reports have been published on sternotomies in patients with a tracheostoma. ${ }^{1,2}$ Mullenix et al. reported on the usefulness of a full sternotomy with a T-shaped skin incision. ${ }^{2}$ Although a full sternotomy may be required for more complicated surgeries such as aortic arch reconstruction, a partial sternotomy is advantageous because the increased distance between the sternotomy and tracheostoma reduces the chance of contamination, and therefore, the risk of wound infection.

In redo cases, various strategies have been advocated to reduce the risk of injury to patent grafts and cardiac structures. ${ }^{3-5}$ Recently, Abe et al. reported that sternal dissection with mobilization of 
a patent graft under thoracoscopic support can be conducted successfully. ${ }^{4}$ However, this approach prolongs the operative time and can be used only in patients with loose adhesions in the thoracic cavity. At our institution, we routinely use peripherally placed CPB to decompress the heart during a redo median sternotomy for a short period of time. We have performed 26 redo sternotomy cases using peripherally placed CPB support in the last three years, and we have found that this technique does not increase the duration of operative time and the amount of blood transfusion compared with the 5 redo cases we performed without CPB support during the same time period. In addition to this strategy, we sometimes use an anterior minithoracotomy to identify patent grafts and dissect them directly, as previously described by Ismail et al. ${ }^{5}$ This technique can also be applied to prevent massive bleeding in patients with ascending aortic aneurysm which adheres to the posterior wall of the sternum. Furthermore, unnecessary adhesiolysis on the posterior wall of the manubrium can be avoided to prevent potentially dangerous communication with the tracheostoma.

In conclusion, a T-shape sternotomy combined with an anterior minithoracotomy is a safe alternative approach for redo surgery in patients with a tracheostoma and patent grafts. 


\section{References}

1. Kaneda T, Saga T, Nishino T, Fujii K, Yukami S. Usefulness of a Partial Median Sternotomy for Acute Infectious Endocarditis in Patients with Tracheostoma. Ann Thorac Cardiovasc Surg $2011 ; 17: 528-530$

2. Mullenix PS, McDonald JM, Miller J, Needham CS. Modified Sternotomy to Minimize Infection Risk in Patients With Prior Laryngectomy and Permanent Tracheostomy. J Card Surg 2006; 21: $403-405$

3. Inafuku H, Ogino H, Sasaki H, Minatoya K, Yagihara T, Kitamura S. Total arch replacement through re-median sternotomy after coronary surgery. Gen Thorac Cardiovasc Surg. 2007; 55: 473-75

4. Abe T, Taniguchi T, Terada T, Sakurai H. Totally endoscopic mobilization of a patent internal thoracic artery graft from the sternum through the left hemithorax in redo coronary artery surgery: A new approach. J Thorac Cardiovasc Surg. 2011; 142: 946-8

5. Ismail I, Zhang R, Ringe K, Fischer S, Haverich A. Retrosternal adhesiolysis through an anterior minithoracotomy: A novel approach facilitating complete median redo sternotomy with a patent internal thoracic artery graft. J Thorac Cardiovasc Surg. 2009; 137: 1034-5 


\section{Figure legends}

\section{Figure 1.}

Preoperative computed tomographic images
A. patent grafts were adhered to the surgical wire
B. the right internal thoracic artery (RITA) crossing the sternum at midline

\section{Figure 2.}

Right anterior minithoracotomy with a midline skin incision at adequate distance from the tracheostomy 

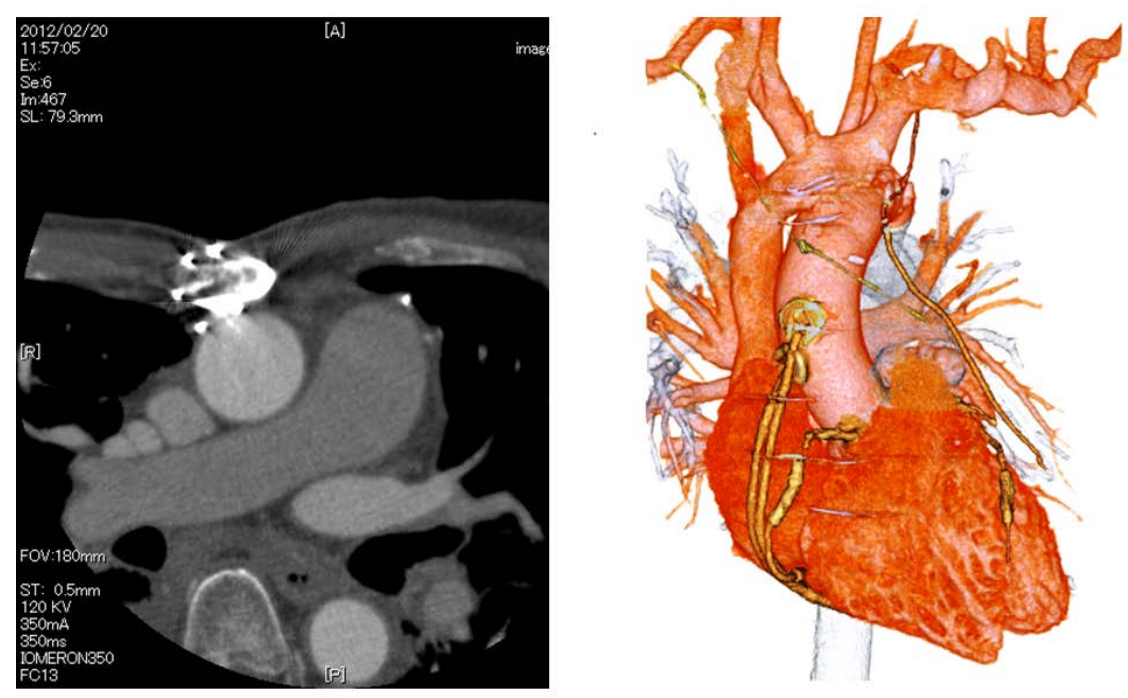

Fig 1.

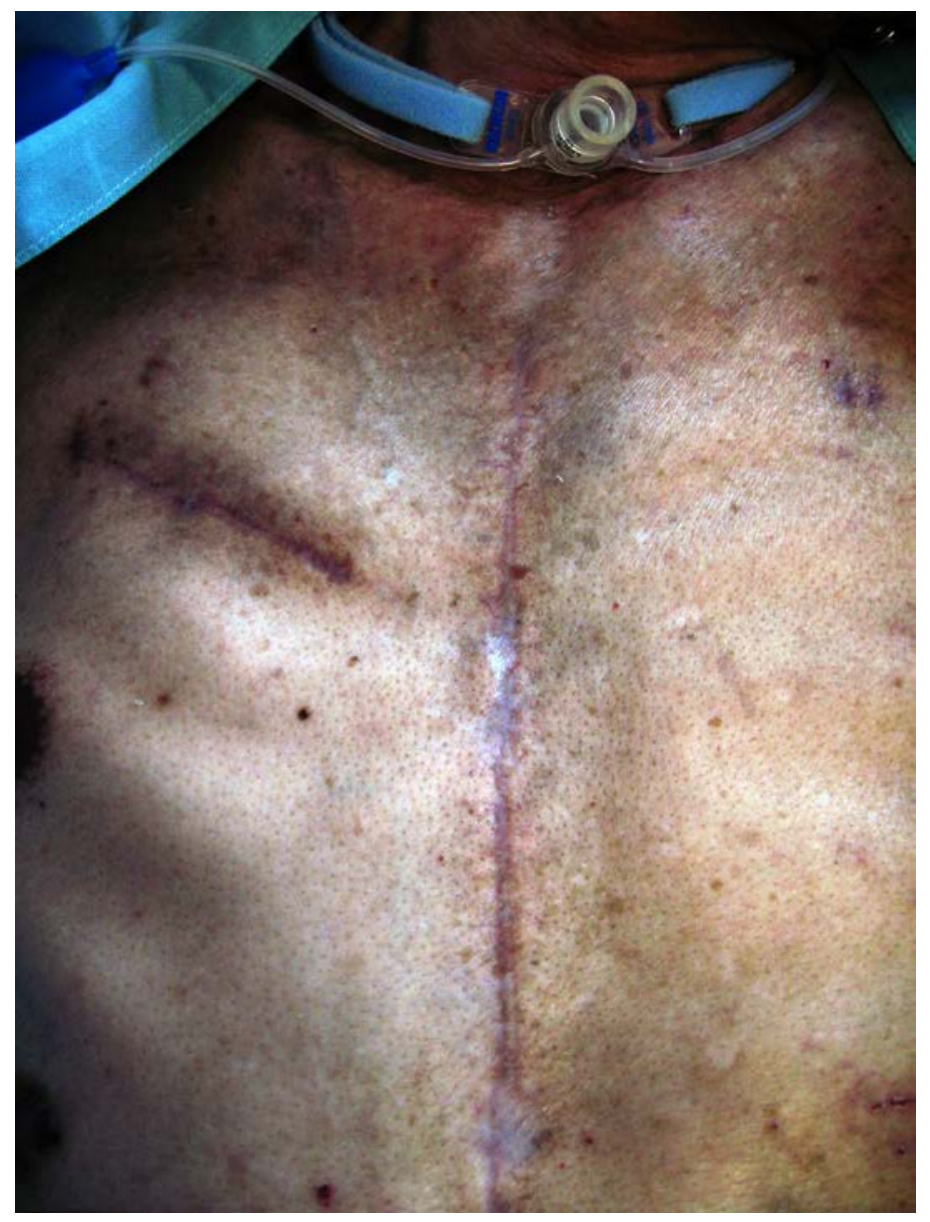

Fig 2 